\title{
Effects of the register to become an organ donor on the organ donation agreement rate
}

\author{
Yuri Chong
}

Korea Organ Donation Agency, Seoul, Korea

Background: In order to increase the deceased donations, it is important to check whether person register to become an organ donor and then, inform their families of their pledges. In Korea, it has been possible to lawfully check the brain-dead persons' register to donate their organs since July 16,2019 . This study aims to analyze such a system to provide for some basic data useful to the activation of the organ donations.

Methods: The researcher sampled 3,284 deceased donor cases notified to Korea Organ Donation Agency for the period from July 16, 2019 until December 31, 2020, and thereby, selected, for a retrospective research, 2,648 cases where the deceased donor register to donate their organs could be confirmed.

Results: Among 2,648 cases where the pledges to donate the organs could be confirmed, the pledges had been registered in 95 cases (3.6\%), while they were not registered in 2,553 cases (96.4\%). Among the 95 pledges registered, 44 ones (46.3\%) had been agreed to the donation by their guardians finally, and among them, 43 cases (45.3\%) were donated finally. In 18 cases, their guardians refused the donation; other family members did not agree to the donation in seven cases (38.9\%), while guardians wanted for an aggressive care, not accepting the reality of the brain dead in two cases (11.1\%). Other reasons for refusal of the donation were 'Did Not Think about Donation' (2 cases; $11.0 \%$ ), refusal of transfer of the body (1 cases; $5.6 \%$ ), refusal of body destruction (1 cases; $5.6 \%$ ), complicated process and procedures for organ donation ( 1 cases; $5.6 \%$ ), religious reasons ( 1 cases; $5.6 \%$ ), and others (3 cases; 16.7\%). Among 2,553 cases where the donation pledges were not registered, final agreements to the donation were made in 724 cases $(28.4 \%)$, and the donations were realized finally in 650 cases $(25.5 \%)$. In this group, the guardians refused the organ donations in 1,050 cases. The major reasons for the refusal were 'desire for an aggressive care' ( 255 cases; $24.3 \%)$, 'Did Not Think about Donation' (185 cases; 17.6\%), 'withdrawal of life-sustaining treatment' (143 cases; 13.6\%), 'other family members refusal' (102 cases; $9.7 \%$ ), and 'refusal of body destruction' (70 cases; $6.7 \%$ ).

Conclusions: During the period, 693 brain-dead persons donated their organ. Forty-three person (6.2\%) of them had registered to donate their organs, while 650 ones (93.8\%) had not. In addition, 70.9\% of those who had registered to become organ donor agreed to the donation, which was $30.2 \%$ higher than the rate of those who had not pledged for the donation (40.8\%). Such a finding proves that it is important to register to become an organ donor to increase the number of deceased donors. To this end, it is essential for the government to increase the relevant budget, while enhancing people's perception of the organ donation though sustainable education and P. R. for more organ donation pledges.

Corresponding author: Yuri Chong

E-mail: yr.chong@koda1458.kr

(c) The Korean Society for Transplantation

This is an Open Access article distributed under the terms of the Creative Commons Attribution Non-Commercial License (http://creativecommons.org/licenses/by-nc/4.0/) which permits unrestricted non-commercial use, distribution, and reproduction in any medium, provided the original work is properly cited. 